\title{
Collapse Analysis of a Reinforced Concrete Frame Due to Middle Column Loss by Explosion
}

\section{Ghada Mousa Hekal*}

Department of Structural Engineering, Faculty of Engineering, Memoufia University, Egypt

\begin{abstract}
The subject of the overall structural collapse under hazardous loads in reinforced concrete frames has been addressed in various researches. However, most of those studies have examined the column removal scenario where one of columns is removed and the load of this column is applied vertically on the upper face to assess the behavior of the frame until failure. One of the shortcomings of the previous mechanism is that it neglects the main reason for the failure of the column and the impact of that reason on the different elements of the structure. The current work presents a numerical investigation of frame collapse as a result of sudden column failure due to an explosive wave. The frame of study has already been tested in a previous work of the author. It was a reinforced concrete frame that has been cast without an intermediate column and then dynamically loaded in the position of the missing column until collapse. In this study, the behavior of that frame is re-evaluated under the effect of instantaneous removal of the middle column due to explosion loads. Analysis was performed using Abaqus software where frame capacity and failure mode were monitored considering different locations of application of incident wave on the target column. Comparing the obtained results with the original model indicated that both capacity and mode of failure differ significantly by changing the location of application of incident wave.
\end{abstract}

Keywords: Explosion impulse load; Reinforced concrete frame; Finite element analysis; Capacity; Failure pattern

\section{Introduction}

Progressive collapse, as described in American Society of Civil Engineers (ASCE) standard 7-05, is the spread of an initial local failure from element to element, eventually resulting in the collapse of an entire structure or a disproportionately large part of it. To occur, progressive collapse needs abnormal loading to initiate damage as well as a structure that lacks adequate continuity, ductility, and redundancy. With repeated catastrophic collapses of many buildings around the world, many research activities have led to more detailed guidelines on preventing progressive collapses [1-3]. A literature survey on the currently used methodologies to avoid progressive collapse is found in preventing disproportionate collapse and progressive collapse of structures [49]. Besides, several research papers have been published presenting both experimental and numerical analysis of progressive collapse in reinforced concrete frames. For example, Brunesi et al. [10] developed fragility functions for low-rise reinforced concrete $(\mathrm{RC})$ framed building structures to be implemented in progressive collapse risk assessment. Two building classes representative of European buildings designed for gravity loads and earthquake resistance in accordance with Euro codes were investigated in the study. Fam and Tan [11] carried out a serious of dynamic tests on two-dimensional reinforced concrete beam-column frames simulating the sudden removal of a supporting column via a quick-release device. Weng et al. [12] traced the collapse sequence of the progressive collapse process using a member removal algorithm based on combined flexural/shear/axial failure criteria. Brodsky and Yankelevsky [13] evaluated the possible contributions of infill masonry walls to prevent progressive collapse. Weng et al. [14] tested three scaled moment-resisting RC frames to validate the proposed flexural and axial damage criteria. In addition, three shear-dominant damaged tests were also modeled by authors to assess the proposed shear damage criteria. Lu et al. [15] conducted laboratory progressive collapse tests of five 1/3scaled RC frame substructure specimens subject to an edge-columnremoval scenario.

In the research presented above, most studied frames have either been cast without a column or the column has been suddenly removed during the test without a dynamic load. However, the main reason of column collapse will certainly have a different effect on the overall structural behavior. Between the various abnormal events, explosions have recently become a major cause of structural collapses due to terrorist threats around the world. Explosion is an instantaneous release of energy resulting in a fast increase in pressure. From the explosion, a wave front is formed and spreads spherically. The temperature and pressure resulting from explosion decrease with increasing distance from the center of detonation. After a few milliseconds the whole process is over, and the pressure returns to atmospheric pressure, $P_{0}$. The typical pressure profile of the explosion wave in time for the explosion in the air is given in Figure 1. At the time of arrival, $t_{a}$, there is an immediate increase in pressure followed by the positive and negative phases. A simplification of the shock wave is often made to make it easier to describe the load that the wave will give rise to. Usually, the negative phase is neglected and the positive pressure is considered as a critical case.

The specific wave impulse, $i$, that is equal to the area under the pressure-time curve from the moment of arrival, $t$, to the end of the positive phase and is given by expression:

$$
i_{s}=\int_{t_{a}}^{t_{a}+t_{0}} P_{s}(t) d t
$$

Based on earlier numerical and experimental studies, many empirical expressions were proposed to calculate Peak static wave front overpressure, $P_{s}$; for example, Brode [16] suggested the following equations:

*Corresponding author: Ghada Mousa Hekal, Faculty of Engineering, Department of Structural Engineering, Menoufia University, Gamal Abd El-Nasr St.-Shebin ElKoum Menofia, Egypt, Tel: 2048 2224216; E-mail: dr_ghekal@hotmail.com

Received March 29, 2017; Accepted May 21, 2018; Published May 24, 2018

Citation: Hekal GM (2018) Collapse Analysis of a Reinforced Concrete Frame Due to Middle Column Loss by Explosion. J Civil Environ Eng 8: 311. doi: 10.4172/2165784X.1000311

Copyright: @ 2018 Hekal GM. This is an open-access article distributed under the terms of the Creative Commons Attribution License, which permits unrestricted use, distribution, and reproduction in any medium, provided the original author and source are credited. 


$$
\begin{array}{ll}
P_{s}=\frac{6.7}{Z^{3}}+1 & \text { For } \mathrm{P}_{\mathrm{s}}>10 \text { bar } \\
P_{s}=\frac{0.795}{Z}+\frac{1.455}{Z^{2}}+\frac{5.58}{Z^{3}}-1.019 & \text { For } 0.1<\mathrm{P}_{\mathrm{s}}<10 \mathrm{bar}
\end{array}
$$

Newmark and Hansen [17] proposed the following:

$$
P_{s}=6874 \frac{W}{R^{3}}+93 \sqrt{\frac{W}{R^{3}}} \text { bar }
$$

and Mills [18] proposed the following:

$$
P_{s}=\frac{108}{Z}+\frac{114}{Z^{2}}+\frac{1772}{Z^{3}}-1.019 \mathrm{kPa}
$$

Where,

$Z$ : Scaled distance, $Z=\frac{R}{\sqrt[3]{W}}$

$R$ : Distance from the center of a spherical charge, $\mathrm{m}$

$W$ : Charge mass expressed in kilograms of TNT.

There is an ongoing effort by researchers to study the influence of the explosions on the various structural elements to develop design methods that lead to better performance under such load condition. (Refer to [19-25] for slabs, [26-31] for columns and [32-34] for beams).

In the current research, it is intended to link both successive collapse and explosion loads by providing a numerical study of a frame under the influence of the collapse of one of its columns due to an explosive wave.

\section{Research Methodology}

\section{Description of the studied frame}

The structure considered in the current study is a two-bay one-story reinforced concrete frame denoted as "FR (1)" in Figure 2. This frame is the front one of two successive frames linked by three secondary beams and having the dimensions and reinforcement details shown in Figures 2 and 3. According to laboratory tests, the compressive strength of concrete was $42 \mathrm{Mpa}$ while the tensile strength of longitudinal steel bars and stirrups were 345 and 250 Mpa respectively. FR (1) was intentionally cast without the intermediate column and formerly tested by loading it dynamically at the position of the removed column until failure to investigate its behavior and capacity under column loss condition [35]. Figure 4 shows test setup of the frame. During the test, the frame was loaded at a rate of $1 \mathrm{t} / \mathrm{sec}$ and the capacity of the frame reached $60.5 \mathrm{kN}$.

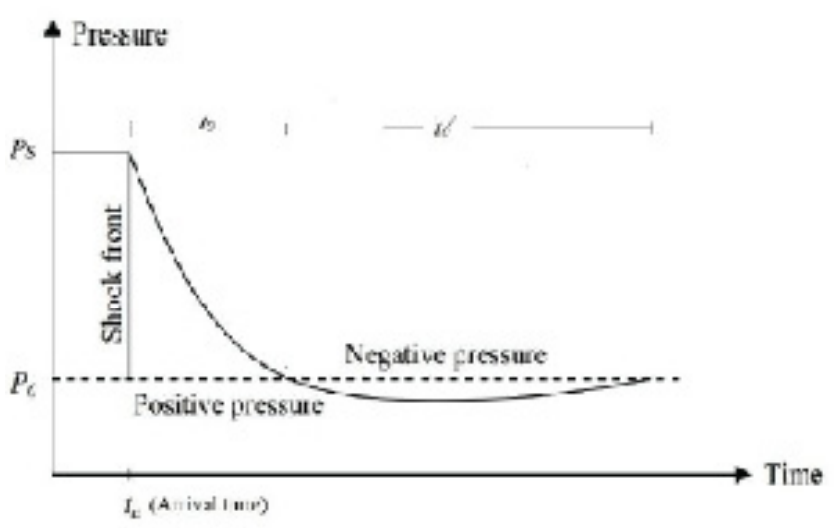

Figure 1: Pressure-time profile of the explosion wave.

\section{Objective of the research}

In the current research, the finite element package, Abaqus, is used to conduct dynamic nonlinear analyses of the previous frame to reevaluate its behavior if the middle column collapsed due to an explosion incident wave. The main aim here is to compare both load-deflection curves and failure patterns of the frame if it was cast from the beginning without a column and if the column exists and then collapsed due to an explosion. In addition, the influence of the location where explosion is applied on the column is studied.

To achieve this goal, a numerical model representing the tested frame was presented and verified against the tested one. Then, the formerly removed column was added to the verified numerical model and loaded by $150 \mathrm{kN}$ distributed as a pressure load on its upper surface. The column was then exposed to a large amount of TNT leading to its total collapse. After column failure, the $150-\mathrm{kN}$ load, carried up to that time by the column, began to transfer to the frame resulting in a progressive collapse.

Four different positions of incident wave action on column were considered in the analysis: the upper part, the middle part, the bottom part as well as the entire front surface of the middle column. In the former three cases, the explosion load was assumed to be acting on an area of $12 \times 25 \mathrm{~cm}$ of the column front surface. Figure 5 sums the different locations considered in the analysis.

\section{Finite Element Model}

Two models were built in Abaqus; a model without the middle
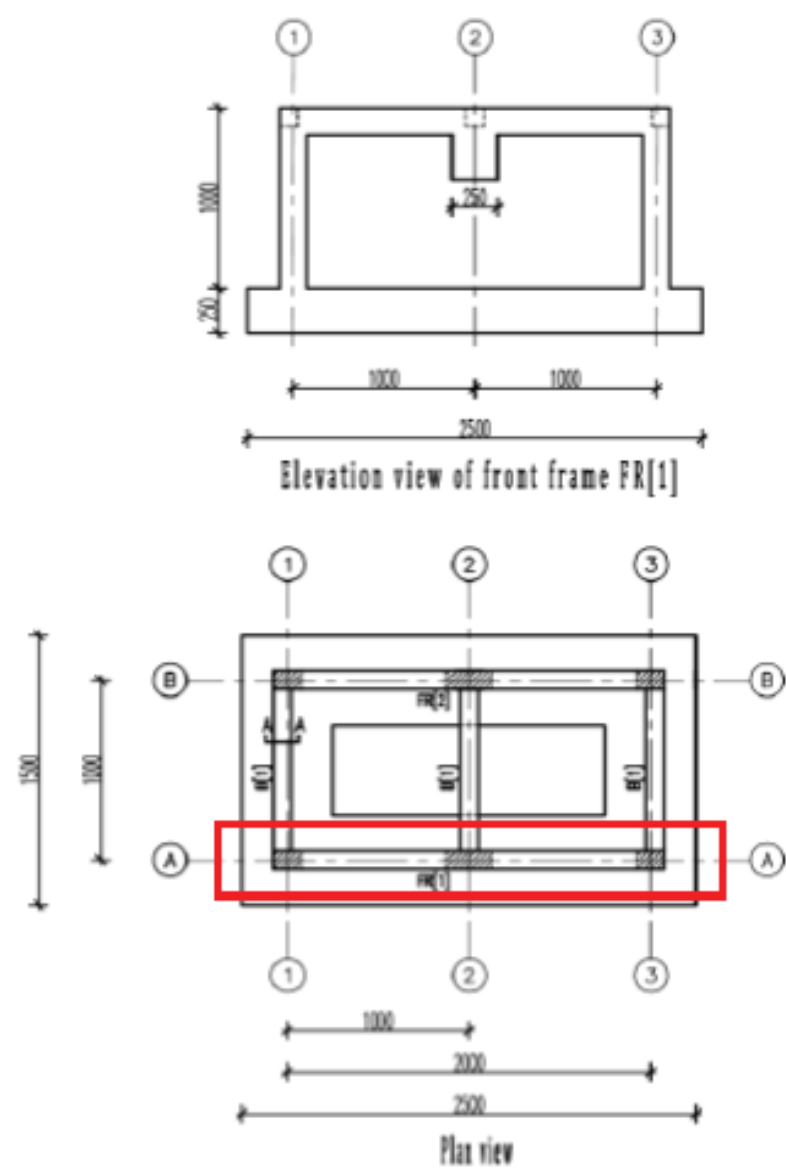

Figure 2: Dimensions of studied frame (Dimensions in $\mathrm{mm}$ ). 

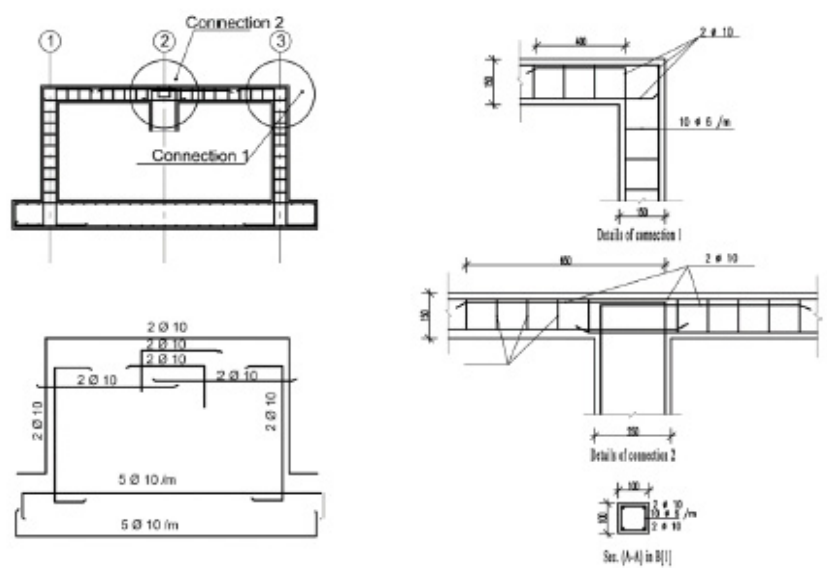

Figure 3: Reinforcement detailing of the studied frame (Dimensions in $\mathrm{mm}$ ).

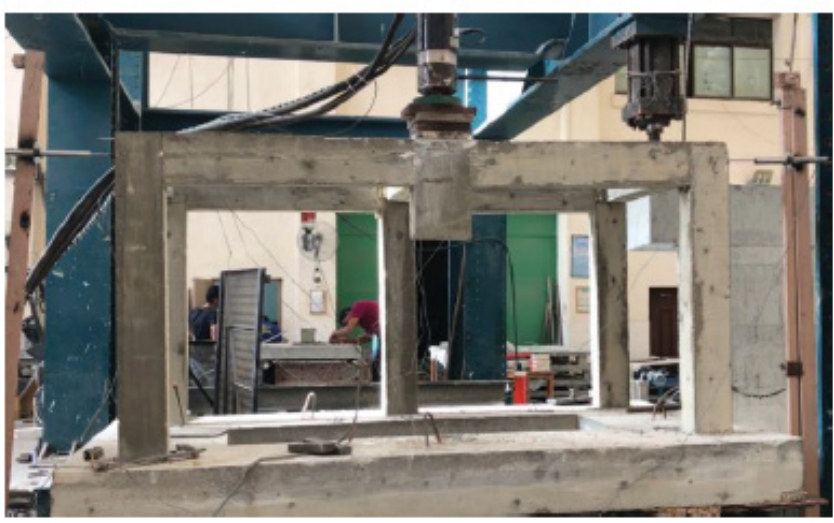

Figure 4: The frame of study as per Tayel et al. [35].

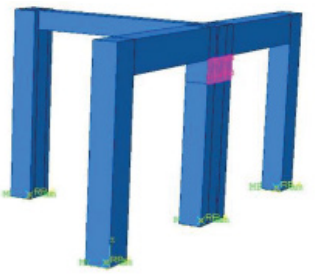

(a) Upper part

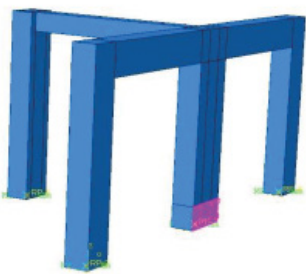

(c) Lower part

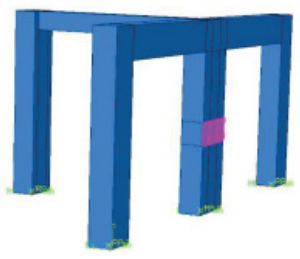

(b) Middle part

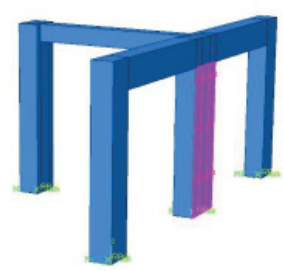

(d) Entire front face
Figure 5: Different locations of application of explosion load on the middle column.

column to represent the experimental one "denoted here as Model (1)", and a model with the middle column that will be exposed to instantaneous collapse due to explosion "denoted here as Model (2)". In both models, the concrete was modelled using reduced order eight-node solid element, C3D8R. The reinforcement bars were modelled as truss elements that were embedded in concrete. Abaqus concrete damaged plasticity model was used to represent concrete material. The dynamic increase factors for compressive and tensile strengths of concrete under high rates of loading, based on test results, were calculated based on the CEB model code [36] and were found to be 1.67 and 2.2 for compression and tension respectively. The main parameters needed to define the concrete model after computation of failure compression and tension strength at high strain rates are summarized in Table 1 while Figure 6 displays the compressive and tension behavior of concrete at static and dynamic loads. Rebar material was modelled using Abaqus elasticplastic model. The main parameters used to define the reinforcement material for both longitudinal bars and stirrups are listed in Tables 2 and 3 respectively. Although FR (1) is the objective in the study, the transverse beam (B1) at the location of loading has been added to the numerical model to study the participation of column (B-2) in the maximum frame capacity after the column collapse in the different considered situations.

\section{Applying Explosion on Abaqus/Explicit}

The loading effects due to an explosion in air were defined in

\begin{tabular}{|c|c|}
\hline 2570 & Density $\left(\mathrm{kg} / \mathrm{m}^{3}\right)$ \\
\hline 25,200 & Young's Modulus: $E(\mathrm{MPa})$ \\
\hline 0.2 & Poisson's ratio \\
\hline 20 & Dilation angle \\
\hline 8.4 & Yield stress in compression $(\mathrm{MPa})$ \\
\hline 70.5 & Compressive ultimate stress $(\mathrm{MPa})$ \\
\hline 0.0018 & Inelastic strain \\
\hline 7.8 & Failure stress in compression $(\mathrm{MPa})$ \\
\hline 0.0056 & Strain at failure \\
\hline 8.4 & Ultimate tensile stress $(\mathrm{MPa})$ \\
\hline $2 \times 10^{-6}$ & Tension stiffening \\
\hline
\end{tabular}

Table 1: Data defines concrete material.

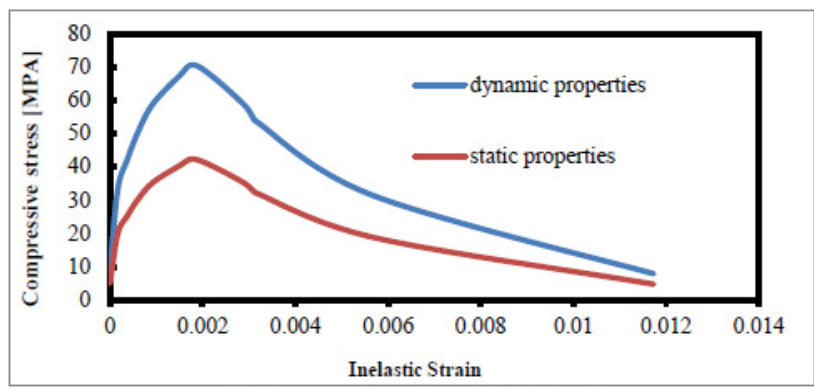

a) Compressive stress-strain behavior

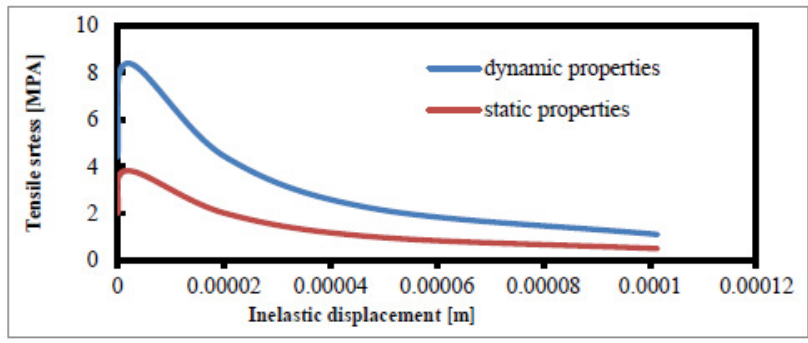

b) Tensile stress- displacement behavior

Figure 6: The compressive and tension behavior at static and dynamic load. 
Citation: Hekal GM (2018) Collapse Analysis of a Reinforced Concrete Frame Due to Middle Column Loss by Explosion. J Civil Environ Eng 8: 311. doi: 10.4172/2165-784X.1000311

Page 4 of 7

Abaqus/Explicit by the CONWEP model. This model uses a scaled distance, $\mathrm{Z}$, based on the distance of the loading surface from the source of the explosion and the amount of explosive detonated. For a given scaled distance, the model provides the following empirical data: the maximum overpressure (above atmospheric), the arrival time, the positive phase duration, and the exponential decay coefficient for both the incident pressure and the reflected pressure. Using these parameters, the entire time history of both the incident pressure and reflected pressure can be constructed. The total pressure $P(t)$, on a surface due to the blast wave is a function of the incident pressure, $P_{\text {incident }}(t)$, the reflected pressure, $P_{\text {reflected }}(t)$, and the angle of incidence, $\theta$, which is defined as the angle between the normal of the loading surface and the vector that points from the surface to the explosion source [37]. The total pressure is defined as:

$$
\begin{array}{lr}
P(t)=P_{\text {incident }}(t) \quad 1+\cos \theta-2 \cos ^{2} \theta+P_{\text {reflected }}(t) \cos ^{2} \theta & \text { for } \cos \theta \geq \\
P(t)=P_{\text {incident }}(t) & \text { for } \cos \theta<0
\end{array}
$$

In Abaqus model, the air blast was defined in interaction module. Based on several trails, the amount of explosive material required to cause failure of column was found to be $100 \mathrm{~kg}$ of TNT. The source point was assumed at 1meter far away from the center of the target surface of the column.

In the model, a vertical pressure was applied on the middle column using an amplitude curve where load gradually increased from zero to $150 \mathrm{kN}$ in $0.007 \mathrm{~s}$. This was found to be the minimum period needed to make the middle column fully loaded by load before applying incident wave, i.e., the time required for the load to reach supports. The load was then kept constant with time till the end of analysis. After $0.007 \mathrm{~s}$, the bomb of $100 \mathrm{~kg}$ TNT was exploded. The applied pressure and source of detonation are shown in Figure 7, while Figure 8 shows the incident wave due to detonation of $100 \mathrm{~kg}$ TNT applied at 1 meter away from

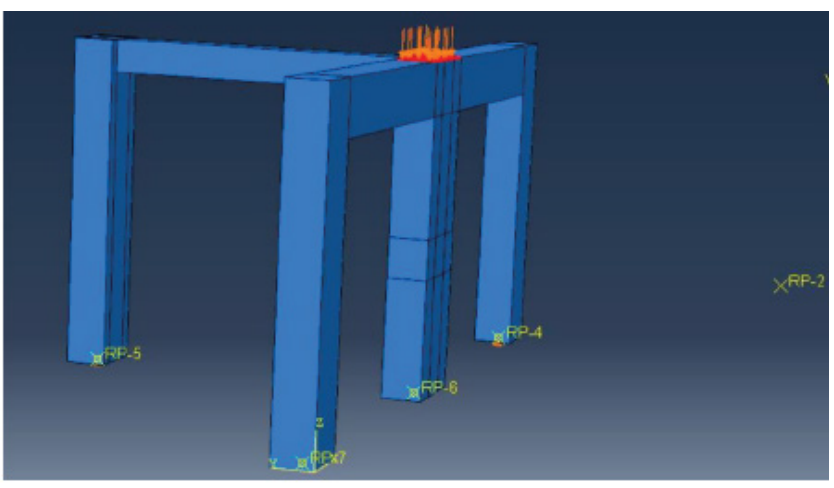

Figure 7: The applied load and source of detonation

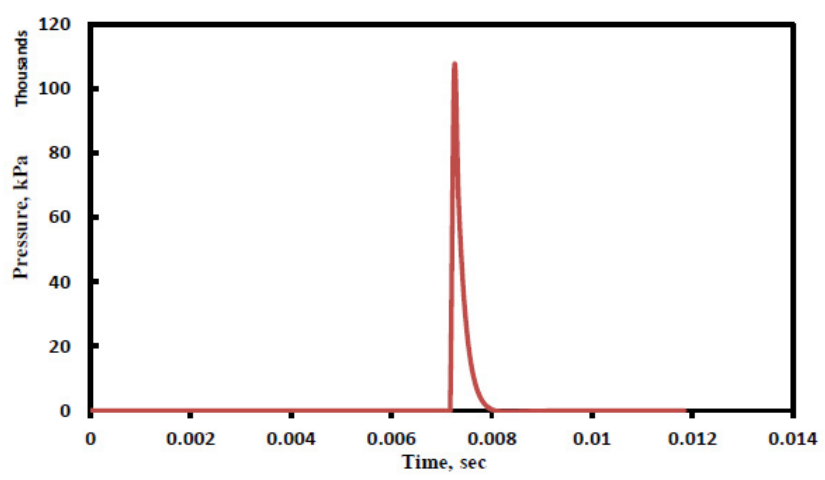

Figure 8: The incident wave due to detonation of $100 \mathrm{~kg}$ TNT. the middle column. The incident wave reached column surface after $0.00025 \mathrm{~s}$ of the detonation with maximum pressure of $1.06 \times 10^{5} \mathrm{~Pa}$ this pressure was rapidly decreased in an exponential manner as shown in figure.

\section{Analysis, Results and Discussion}

\section{Comparison between model (1) and experimental results}

Figure 9 compares the failure modes in the tested frame and Model (1). It is clear that the shape of collapse is identical in both experimental model and numerical Model (1) where the collapse occurred beside connection 1 and at connection 2 in one side. The load-deflection relationships is also plotted in Figure 10 which shows fair agreement where the maximum capacity in the tested frame reached $60.5 \mathrm{kN}$ at deflection $24 \mathrm{~mm}$ while in Model (1) the capacity is $60.25 \mathrm{kN}$ at $20 \mathrm{~mm}$ deflection.

\section{Comparison between Model (1) and Model (2)}

Load deflection relationships and failure patterns for the all studied cases are summed in Figures 11 and 12 respectively. Besides, the participating ratios of column (B-2) in the total capacity in all cases are presented in Table 4. In general, it can be observed that when the explosion was applied to the column, the load-deflection relationships as well as the frame collapse patterns differed significantly from Model (1), where the four cases of Model (2) showed a symmetrical pattern of failure and irregular shapes of load-deflection curves in contrast to Model (1)

Moreover, the total behavior of frame was strongly dependent on the location of application of explosion load. When explosion was applied at the upper part of the column, the capacity decreased to $51 \mathrm{kN}$ at $2 \mathrm{~mm}$ indicating a sudden failure. The same case appeared when the explosion was applied to the entire column face as the capacity was 46
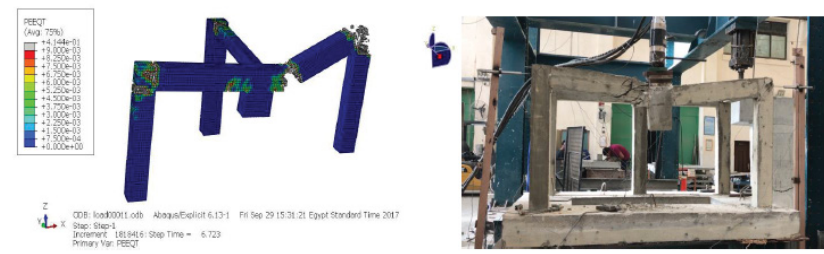

Figure 9: Modes of failure in both experimental and FE Model 1.

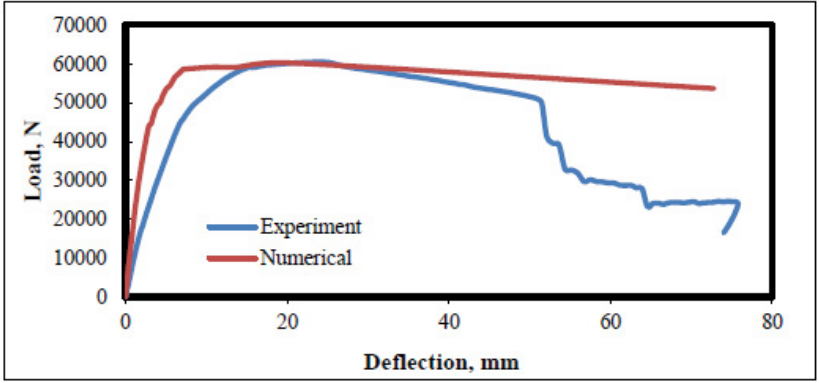

Figure 10: Vertical load-deflection relationships at middle column.

\begin{tabular}{|c|c|}
\hline 7800 & Reference density $\left(\mathrm{kg} / \mathrm{m}^{3}\right)$ \\
\hline $2,00,000$ & Young's Modulus, $\mathrm{E}(\mathrm{MPa})$ \\
\hline 345 & Tensile Strength, $\mathrm{f}_{\mathrm{t}}(\mathrm{MPa})$ \\
\hline
\end{tabular}

Table 2: Data defines longitudinal steel material. 
Citation: Hekal GM (2018) Collapse Analysis of a Reinforced Concrete Frame Due to Middle Column Loss by Explosion. J Civil Environ Eng 8: 311. doi: $10.4172 / 2165-784 X .1000311$

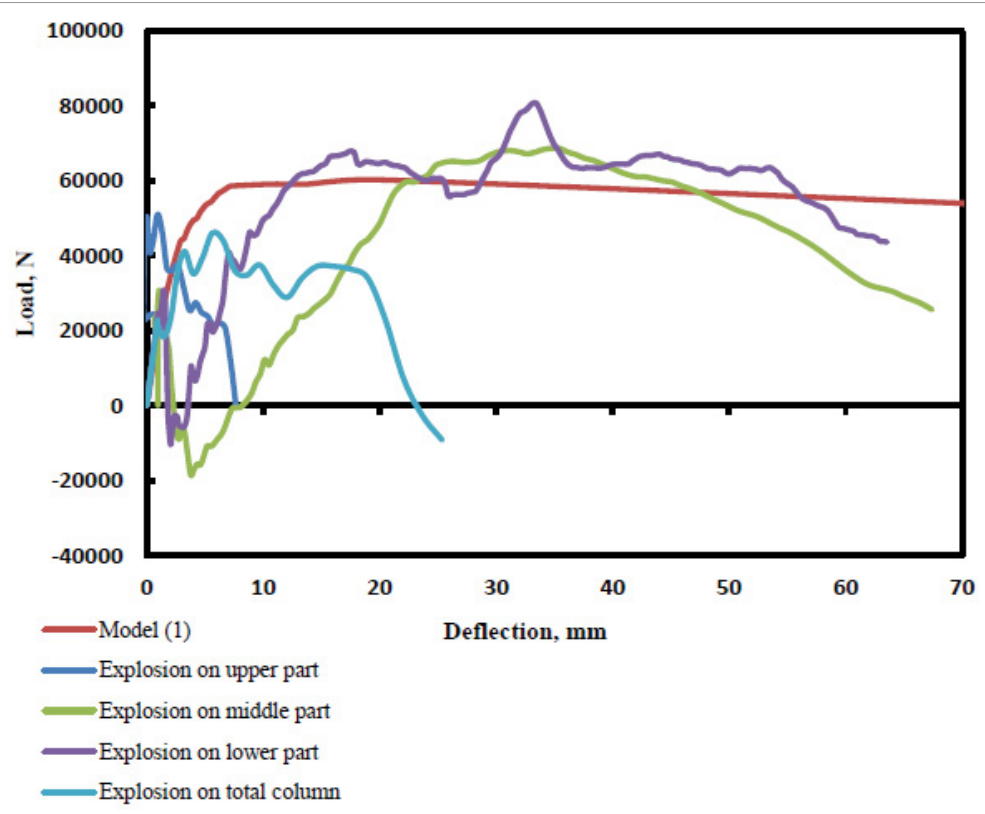

Figure 11: The load-deflection relationships at middle column due to explosion load.
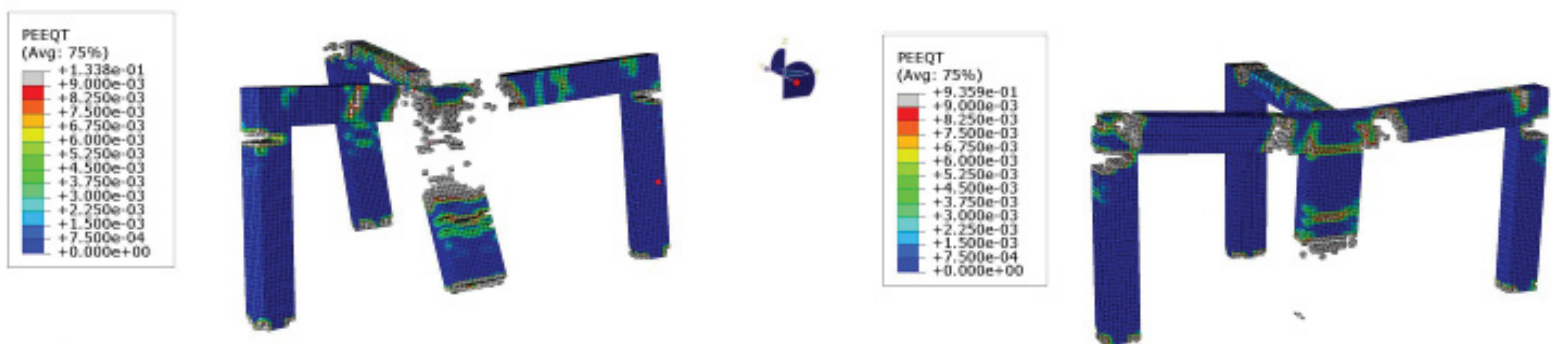

Y ODB: upper.odb Abaqua/Explict 6.14-2 Wed Feb 14 16:36:18 Egypt Standard Time 2018

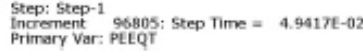

(a) Explosion on upper purt of the cohmon

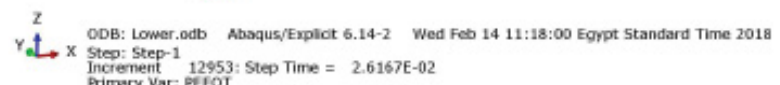

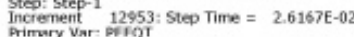

(c) Explosion on middle part of the cohmm
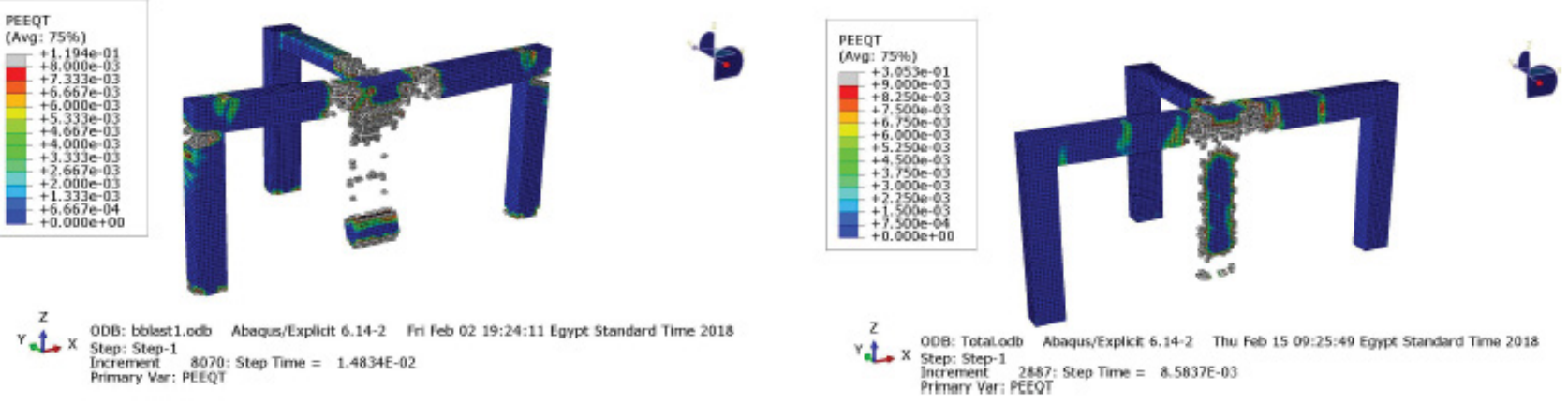

(b) Explosicen on middle part of the colvmen

(d) Explosion on the cative frout face of the colimn

Figure 12: Failure pattern of the frame in the four cases of Model 2.

\begin{tabular}{|c|c|}
\hline 7800 & Reference density $\left(\mathrm{kg} / \mathrm{m}^{3}\right)$ \\
\hline $2,00,000$ & Young's Modulus, $\mathrm{E}(\mathrm{MPa})$ \\
\hline 250 & Tensile Strength, $\mathrm{f}_{\mathrm{t}}(\mathrm{MPa})$ \\
\hline
\end{tabular}

Table 3: Data defines stirrups steel material.

\begin{tabular}{|c|c|c|c|c|c|}
\hline $\begin{array}{c}\text { Percentage of } \\
\text { total capacity } \\
\text { \% }\end{array}$ & $\begin{array}{c}\text { Model } \\
\text { (1) }\end{array}$ & $\begin{array}{c}\text { Upper } \\
\text { explosion }\end{array}$ & $\begin{array}{c}\text { Middle } \\
\text { explosion }\end{array}$ & $\begin{array}{c}\text { Lower } \\
\text { explosion }\end{array}$ & $\begin{array}{c}\text { Explosion } \\
\text { on total } \\
\text { column }\end{array}$ \\
\cline { 2 - 5 } & $6.70 \%$ & $59 \%$ & $20 \%$ & $23 \%$ & $54.50 \%$ \\
\hline
\end{tabular}

Table 4: The percentage of reaction at column (B-2) of total capacity of frame when explosion was applied at different position of column. 
$\mathrm{kN}$ and the deflection was $6 \mathrm{~mm}$. Application of blast at middle part of column led to a capacity of $69 \mathrm{kN}$ at $35 \mathrm{~mm}$ deflection while exploding the lower part of the column raised the capacity to $81 \mathrm{kN}$ at $33 \mathrm{~mm}$ deflection.

The previous values indicate that the worst case appeared when explosion was applied at the upper part of column while the performance of the frame got better as the location of explosion moved away from the connection as the frame showed a remarkable increase in capacity.

The ratio of column B2 participation in the overall capacity reached $59 \%$ and $54.5 \%$ when explosion was applied at upper part and on the entire front face of the column respectively. This ratio decreased to $20 \%$ and $23 \%$ at middle and lower explosion. In contrast, column participation was only $6.7 \%$ in case of Model (1).

\section{Conclusions}

The main findings of the current work can be summarized as follows:

1. Finite element model results showed fair agreement with the tested frame regarding to mode of failure and load-deflection relationships.

2. Concrete at high strain rate has higher properties in both tension and compression which significantly affects the structural behavior in the numerical model.

3. The total behavior and failure pattern of the frame is significantly influenced by the nature and position of applications of the explosion load. So, the common methods followed to study progressive collapse by removing some elements don't represent the real behavior as they ignore the main reason of collapse.

4. Beside the damage that occurred in frame FR (1), there was damage that observed in the transverse beam and hence column B-2 participated in total capacity of the structure. This indicated that considering $2 \mathrm{D}$ structures only is not enough to express the real behavior of a structure.

\section{References}

1. GSA Guidelines (2003) GSA progressive collapse analysis, Design guidelines for new federal office buildings, Major Modernizations Projects. General Services Administration (GSA).

2. DoD UFC Guidelines (2005) Design of buildings to resist progressive collapse, Unified Facilities Criteria (UFC) 4-023-03. Department of Defence (DoD)

3. NIST Best Practices (2005) Best practices for reducing the potential for progressive collapse in buildings. US National Institute of Standards, Technology (NIST), Washington, DC, USA.

4. Nair RS (2006) Preventing disproportionate collapse. J Perform Construct Facilit 20: 309-314

5. Mohamed OA (2006) Progressive collapse of structures: Annotated bibliography and comparison of codes, standards. J Perform Construct Facility 20: 418-425.

6. Starossek U (2009) Progressive collapse of structures. Thomas Telford Ltd, UK.

7. Kokot S (2009) Literature survey on current methodologies of assessment of building robustness and avoidance of progressive collapse.

8. Starossek U (2007) Typology of progressive collapse. Engineering Structures 9: 2301-2307.

9. Marjanishvili S, Agnew E (2006) Comparison of various procedures for progressive collapse analysis. J Perform Construct Facilit 20: 365-374.

10. Brunesi E, Nascimbene R, Parisi F, Augenti N (2015) Progressive collapse fragility of reinforced concrete framed structures through incremental dynamic analysis. Engineering Structures 104: 65-79.
11. Pham A, Tan K (2017) Experimental study on dynamic responses of reinforced concrete frames under sudden column removal applying concentrated loading Engineering Structures 139: 31-45.

12. Weng J, Tan K, Lee C (2017) Modeling progressive collapse of 2D reinforced concrete frames subject to column removal scenario. Engineering Structures 141: $126-143$.

13. Brodsky A, Yankelevsky D (2017) Resistance of reinforced concrete frames with masonry infill walls to in-plane gravity loading due to loss of a supporting column. Engineering Structures 140: 134-150.

14. Weng J, Lee C, Tan K, Salim N (2017) Damage assessment for reinforced concrete frames subject to progressive collapse. Engineering Structures 149 : 147-160.

15. Lu X, Lin K, Guan H, Ren P, Zhou Y (2017) Experimental investigation of RC beam-slab substructures against progressive collapse subject to an edgecolumn-removal. Engineering Structures 149: 91-103.

16. Brode HL (1955) Numerical solution of spherical blast waves. Journal of Applied Physics, American Institute of Physics, New York, USA

17. Newmark NM, Hansen RJ (1961) Design of blast resistant structures. Shock, Vibration H,book, Vol. 3, Eds. Harris, Crede. McGraw-Hill, New York, USA.

18. Mills CA (1987) The design of concrete structure to resist explosions and weapon effects. Proceedings of the 1st Int. Conference on concrete for hazard protections, Edinburgh, UK. pp: 61-73.

19. Thiagarajan G, Anirudha V, Robert S (2014) Experimental and finite element analysis of doubly reinforced concrete slabs subjected to blast loads. Int $J$ Impact Eng 75: 162-173

20. Li J, Wu C, Hao H, Wang Z, Su Y (2015) Experimental investigation of ultrahigh performance concrete slabs under contact explosions.Centre for Built Infrastructure Research. Int J Impact Eng 93: 62-75.

21. Li J, Wu C, Hao H, Su Y, Xian Z (2017) A study of concrete slabs with stee wire mesh reinforcement under close in explosive loads. Int J Impact Eng 110 242-254

22. Li J, Wu C, Hao H (2015) Investigation of ultra-high performance concrete slab, normal strength concrete slab under contact explosion. Engineering Structures 102: 395-408.

23. Tai Y, Chu T, Hu H, Wu J (2011) Dynamic response of a reinforced concrete slab subjected to air blast load. Theor Appl Fract Mec 56: 140-147.

24. Zhao C, Chen J (2013) Damage mechanism, mode of square reinforced concrete slab subjected to blast loading. Theor Appl Frac Mec 63-64: 54-62.

25. Li J, Wu C, Liu Z (2017) Comparative evaluation of steel wire mesh, steel fiber high performance polyethylene fiber reinforced concrete slabs in blast tests. Thin-Walled Structures 2: 1.

26. Yuan S, Hao H, Zong Z, Li J (2017) A study of RC bridge columns under contact explosion. Int J Impact Eng 109: 378-390.

27. Fujikake K, Aemlaor P (2013) Damage of reinforced concrete columns under demolition blasting. Engineering Structures 55: 116-125.

28. Parisi $F$ (2015) Blast fragility, performance-based pressure-impulse diagrams of European reinforced concrete column Engineering Structures 103: 285-297.

29. Xu J, Wu C, Xiang H, Su Y, Xian Z, et al. (2016) Behavior of ultra-high performance fibre reinforced concrete columns subjected to blast loading. Engineering Structures 118: 97-107.

30. Zhang F, Wu C, Zhao X, Heidarpour A, Li Z (2017) Experimental and numerical study of blast resistance of square CFDST columns with steel-fibre reinforced concrete. Engineering Structures 149: 50-63.

31. Kyei C, Braimah A (2017) Effects of transverse reinforcement spacing on the response of reinforced concrete columns subjected to blast loading. Engineering Structures 142: 148-164

32. Qu, Y, Li X, Kong X, Zhang W, Wang X (2016) Numerical simulation on dynamic behavior of reinforced concrete beam with initial cracks subjected to air blast loading. Engineering Structures 128: 96-110.

33. Chen W, Hao H, Chen S (2015) Numerical analysis of prestressed reinforced concrete beam subjected to blast loading. Materials \& Design 65: 662-674

34. Qu Y, Liu W, Gwarzo M, Zhang W, Zhai C, et al. (2017) Parametric study of antiexplosion performance of reinforced concrete T-shaped beam strengthened with steel plates. Constr Build Mater 156: 692-707. 
Citation: Hekal GM (2018) Collapse Analysis of a Reinforced Concrete Frame Due to Middle Column Loss by Explosion. J Civil Environ Eng 8: 311. doi: 10.4172/2165-784X.1000311

35. Tayel M, Hekal G, Ali I (2018) Experimental study and numerical analysis of progressive collapse resistance of a reinforced concrete frame. $12^{\text {th }}$ International Conference on Civil and Architecture Engineering, ICCAE-12, The Military Technical College, Cairo, Egypt.
36. Comité Euro-International du Béton (1993) CEB-FIP Model Code 1990, Redwood Books, Trowbridge, Wiltshire, UK

37. Abaqus Explicit User's Manual (2008) Hibbitt, Karlesson and Sovensen, Inc Vol. 1, Version 6.8-1, USA. 